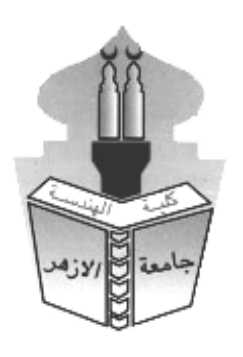

\title{
INTER-STOREY DRIFT AND SEISMIC RESPONSE OF HIGH-RISE BUILDINGS WITH TRANSFER SLABS
}

\author{
Yasser M. Abdlebasset ${ }^{1}$, Ezzeldin Y. Sayed-Ahmed ${ }^{2}$ and Sherif A. Mourad ${ }^{3}$ \\ ${ }^{1}$ Faculty of Engineering, Cairo, University Cairo University, Egypt \\ ${ }^{2}$ Structural Eng. Dept., Ain Shams University, Egypt, \\ ${ }^{3}$ Structural Engineering Dept., Faculty of Engineering, Cairo, University,
}

\begin{abstract}
الملخص
يحتوي هذا البحث علي دراسة نظرية لسلوك المنشأت الخرسانية الغير منتظمة رأسيا والتي قد تستخدم لتحقيق متطلبات

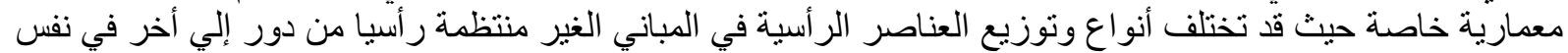

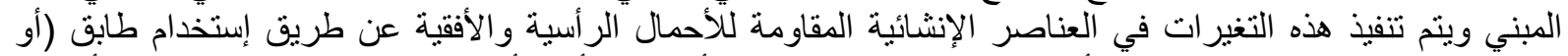

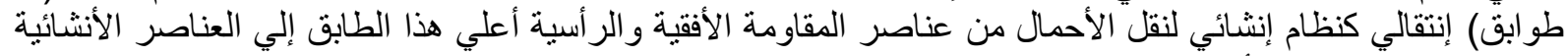
المختلفة التوزيع و النوع أسفل الطابق النقابق الإنتقالي.

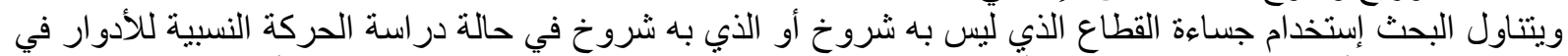

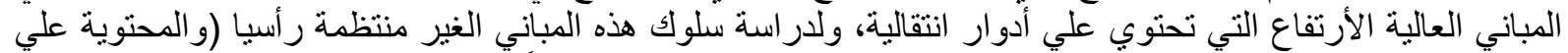

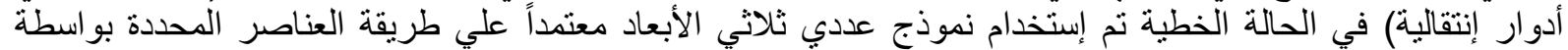

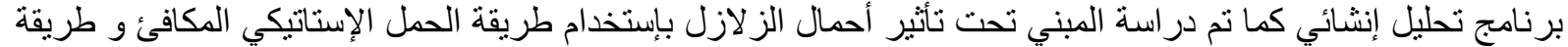

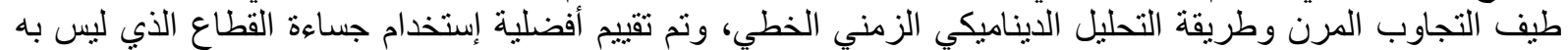
شروخ أو الذي به شروخ في حالة دراسة الحركة النسبية للأدوار في المباني العالية الإرتفاع التي تحتوبي علّي أدوار

إنتقالية.
\end{abstract}

\begin{abstract}
In many high-rise buildings, architectural requirements may result in a variable configuration for the vertical structural elements between the stories of the building. To accommodate such vertical elements discontinuity, a "transfer" floor conveying vertical and lateral loads between upper and lower stories must be introduced. A drawback of the transfer floor is the sudden change in the building's lateral stiffness at its level: the structure becomes susceptible to the formation of a soft-story mechanism under moderate to severe earthquakes. These buildings generally showed conventional elastic behavior for minor earthquakes but suffer extensive crack in the vicinity of transfer floors for major earthquakes. However, for design purposes current numerical modeling of high-rise building adopts reduced stiffness for the vertical elements for strength analysis and full stiffness for serviceability and drift analysis: a tradition that needs to be verified. A 3-D numerical model is built-up for a high-rise building with such vertical irregularities and analyzed using elastic response spectrum and nonlinear time-history analysis techniques. The effect of transfer floors on the buildings drift is investigated where judgment for adopting a full or reduced stiffness for the vertical elements is scrutinized. Keywords: drift, response spectrum, stiffness, seismic loads, time history, transfer floor.
\end{abstract}

\section{INTRODUCTION}

Recently, innovative architectural design merged with the advanced and powerful structural numerical analysis stimulated a new generation of "super-tall" and "mega-tall" buildings. 
Furthermore, discontinued vertical elements (columns and shear walls) within high-rise buildings are no more considered as a sin. Consequently, architectural demands for high-rise buildings in which columns may have different arrangement in a certain level(s) become familiar. Many high-rise buildings are currently constructed with this kind of vertical irregularity where "transfer" floors are provided to account for the discontinuous vertical element (columns and/or shear walls) to accommodate the functions (Figure 1).

Transfer floor is the floor system supporting the vertical and lateral load resisting elements and transfer their straining actions to a different underneath system. Different structural systems could be used for such buildings as the resisting system below the transfer floor may be moment-resisting frames and/or core walls while the floors above may be supported by structural walls. The transfer structures could be in form of transfer girders or slabs.

A major drawback of any transfer floor is the abrupt change in the building's lateral stiffness in the vicinity of its level. A direct consequence of such irregularity is that the deformation of a soft-story mechanism under moderate to severe earthquakes or lateral wind loads imposes high ductility demands on the elements in the vicinity of the transfer floors [1].

Therefore, if this irregularity is not taken into consideration during design stages, the structural irregularity can become a major source of building damage during strong earthquakes. A recent research [2,3] pointed out to the adverse effect of the drift in the vicinity of the transfer floor on the level of damage occurring to these buildings. The said investigation along with another investigation [4] also showed the significant effect of the lateral flexure and shear stiffness of the vertical elements above/below the transfer level on the drift values. These findings can be correlated to the outcomes of an older investigation $[5,6]$ where drifts are pronounced by reducing the stiffness of these vertical element; hence, revealing the importance of deciding to consider a reduced or a full stiffness for the vertical structural elements (columns and shear walls) in any numerical model of high-rise buildings with transfer floors.

High-rise buildings with transfer floors generally suffer no cracks (conventional elastic behavior) when subject to minor earthquakes. However, severe cracking in the vicinity of the transfer floor is encountered when these buildings are subjected to medium or major earthquakes. Despite this fact, reduced stiffness for "cracked" vertical structural elements (columns and walls) is normally adopted for strength design of these buildings while full stiffness is adopted for serviceability and drift design: a strategy which needs to be scrutinized.

This work presents the first milestone of a wider research that serves to either verify the previously mentioned analysis strategy for drift calculations or suggest a suitable alternative and, if so, recommends quantification for the reduction of the vertical elements stiffness when performing serviceability/drift design under seismic loads. An analytical seismic study for the response of high-rise buildings with transfer floors is carried out via 3-D modeling of these buildings using the finite element technique. The numerical models are analyzed using elastic response spectrum and time-history analysis techniques. The effect of transfer floors on the drift of such structures is investigated: adopting full or reduced stiffness for the vertical elements in the numerical models will be scrutinized. 

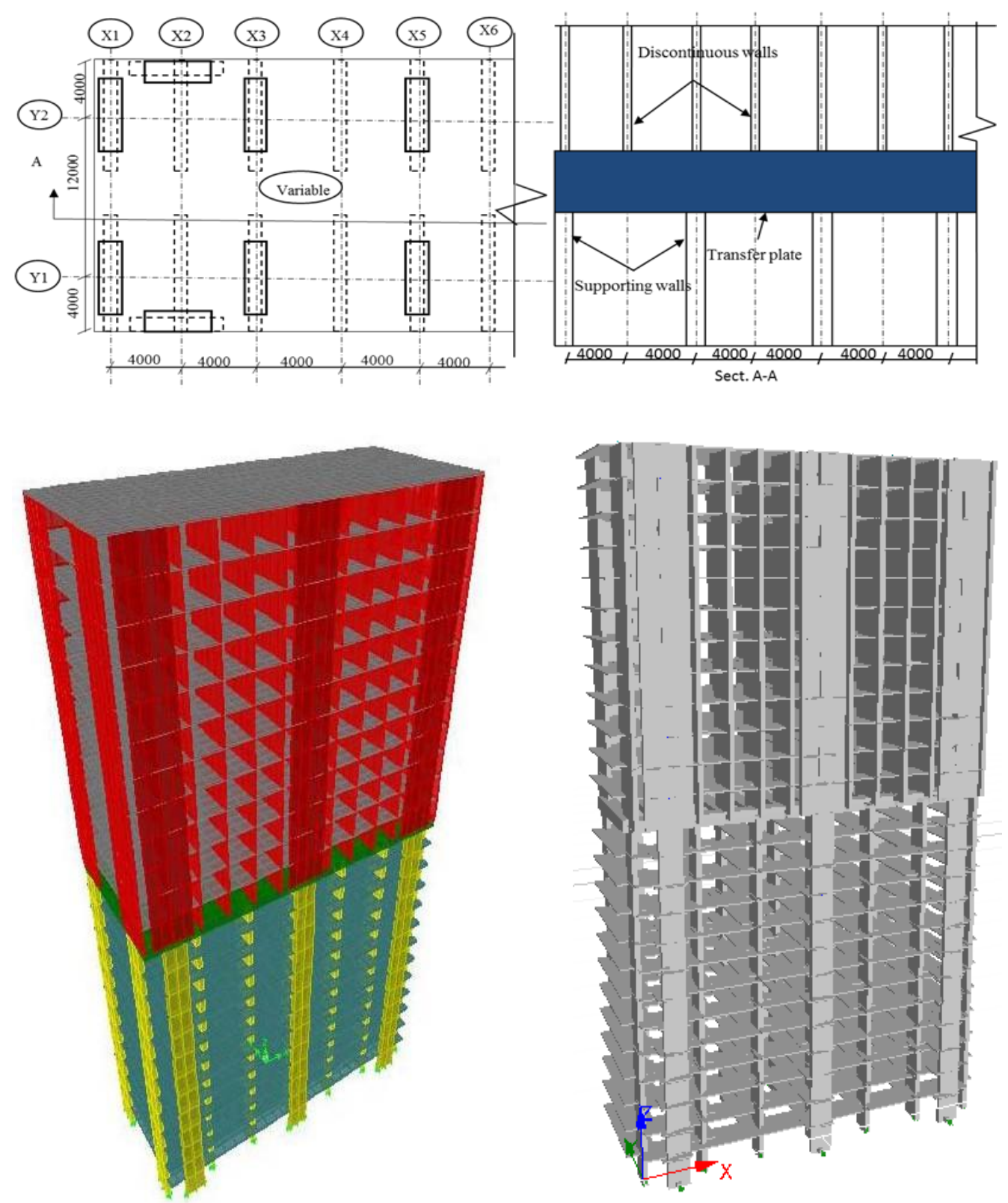

Figure 1: A prototype building (above) for part of a transfer slab with vertical elements arrangement above and below the slab and a typical numerical model (below) of such buildings showing vertical elements above and below the slab.

\section{Methodology}

The research has a numerical nature; it is performed using numerical modelling of prototypes for high-rise buildings with transfer floors. These prototypes are modified from real high-rise buildings which have already been designed and constructed. Three-dimensional finite element models for prototype buildings with transfer floors are built-up. The seismic response of these buildings is investigated using elastic response spectrum and time history analysis techniques as a first step of a wider research. The story shear distribution, bending moment distribution, inter-storey drift, floor displacements and accelerations are numerically evaluated and compared to their values deducted via codes of practice.

Using the three-dimensional models, investigation into considering "full" and/or "reduced" stiffness of the vertical structural elements (columns and shear walls) are carried out. Linear time history analysis model will present the benchmark for the drift calculations where recommendations on using the "full" or the "reduced" stiffness for these vertical structural elements is given after comparing the time history model results to the outcome of the 
common analysis strategies which are currently adopted in design offices.

\section{Case Study of a High-Rise Building with Transfer Slab}

The numerical investigation presented herein is intended to investigate the linear elastic seismic behavior of structural wall buildings with transfer floors. The study considers only one type of transfer: solid transfer plates (slabs). Transfer slab system easily accommodates the difference in the location of the vertical load bearing elements above and below its level.

A parametric study was conducted on a prototype building with total number of 50 stories with a transfer floor. The transfer floor (slab) is located at $20 \%$ of the building height. The level of the transfer slab with respect to the building height is selected based on the outcomes a previous investigation [2,7]. Analytical results of this research present a comparison between various configurations for the stiffness (moment of inertia) of the different building structural elements; the transfer floor system and its location within the building height were kept fixed during this comparative study. These results cover the global behavior of the structures i.e., shear distribution and values, base shear, moment distribution and values, drift distribution and values, displacement distribution and values, structure periodic time/frequency and mass participation ratio.

\section{Seismic load input}

In most cases, earthquakes are a result of sudden slip of geotechnical fault at the intersection of two tectonic plates. It results in a release of energy from the focus of the earthquake propagating in the form of waves travelling through the earth crust and causing vibration on the earth's surface. This energy is transmitted from the ground to the base of the structure causing vibration to its structural elements. Structural damage may result since the ground motion is amplified when transmitted from the ground to the structure. This amplification in forces depends on the fundamental period of the structure and a lot of other factors influencing the ground motion. Amplified forces and displacement are in most cases greater than the capacity of the structure.

Earthquake ground motion at a site is developed either from recorded actual earthquake using strong motion instruments recording the acceleration of the ground, artificial earthquake records, or using empirical relationships based on past records. Recorded strong ground motion gives the most accurate data that can be relied on in design, consisting of acceleration traces of motion along the two horizontal directions and in the vertical direction. The most important characteristics of earthquake ground motion are: peak ground motion (peak ground acceleration, peak ground velocity, and peak ground displacement), duration and frequency content. Peak ground acceleration (PGA) is considered one of the most important characteristics of earthquake ground motion, and in most cases is presented as a percentage of ground acceleration (g). Duration of ground motion has a pronounced effect on the damage of the structure. The longer the duration of the strong shaking, the larger the energy transmitted to the structure. Frequency content relates to the frequency of the vibration of the structure, since it determines the degree of amplification of the forces transmitted from the ground to the structure.

According to most previous researches and codes of practice, there are two types of seismic analysis for buildings: linear-elastic and non-linear methods linear elastic methods include equivalent lateral force analysis (ELF), linear elastic response spectrum analysis (LERS) and linear time history analysis (LTH) while non-linear methods include non-linear static "pushover" (NLSP) analysis and non-linear time history analysis (NLTH).

Here, equivalent lateral force, elastic response spectrum and linear time history analyses were performed on the models to evaluate the base shear, the overturning moments, the shear distribution along the building height, the periodic time, the participation ratios, the displacement and the story drift for the first twelve modes of the modelled building using CQC (complete quadratic combination) combining sequence.

\section{Linear equivalent static load}

The concept employed in equivalent static lateral force procedures is to place static loads on a structure with magnitudes and direction that closely approximate the effects of dynamic loading caused by earthquakes. Furthermore, concentrated lateral forces tend to be larger at higher elevations in a structure. Thus, the greatest lateral displacements and the 
largest lateral forces often occur at the top level of a structure (particularly for tall buildings). These effects are modelled in equivalent static lateral force procedures of the ASCE, IBC and UBC by placing a force at each story level in a structure.

In general, the distribution of lateral story forces is associated with the first (fundamental) mode of vibration of a cantilevered structure. In this case, a typical structure is idealized as a vertical cantilever rigidly attached to the ground. The effects of higher modes of vibration are approximated in codes of practice by considering an additional lateral force applied to the top level of a structure. In most codes of practice, the summation of the lateral story forces must be equivalent to the base shear (V) force applied to the structure due to seismic ground motion.

Thus, according to the ASCE 07-10 provisions, the seismic parameters, related to this location, were found to be as following: the $0.2 \mathrm{sec}$ spectral acceleration $\mathrm{Ss}=0.5$, the $1.0 \mathrm{sec}$ spectral acceleration $S 1=0.117$, long period transition period $=20$ and the soil type is $B$ (very dense soil and soft rock). The numerical coefficient (R) which is representative of the inherent over strength and global ductility capacity of lateral force-resisting systems was found to be 5.0 , system over-strength $\left(\Omega_{0}\right)$ was found to be 2.5 , deflection amplification factor $\left(C_{d}\right)$ was found to be 4.5 and the building importance factor (I) will be 1.25 . The numerical coefficient $\left(C_{t}\right)$ was found to be 0.02 . For mass source, dead loads factor was taken to be 1.0 and live loads factor was taken to be 0.50 .

\section{Linear elastic response spectrum analysis (LERS)}

The response spectrum presents the maximum response of a structure to a given earthquake ground motion. It is a plot of the maximum response of damped single degree of freedom oscillator for all possible frequencies or period of as system. The response spectra for a given earthquake record is quite irregular and has a number of peaks and valley. The irregularities are sharp for small damping ratio and become smooth as the damping increase. Design codes have presented response spectra in term of PGA because of the greater availability of predicted models and observation data for this strong motion intensity measure. It is predicted from empirical relationships between the earthquake magnitude and peak acceleration. Response spectrum for design is presented in terms of acceleration amplification as a function of the period plotted on an arithmetic scale.

A lot of factors affect the shape of the response spectra among them are: earthquake magnitude and duration, epicentre distance, fault mechanism and geometry, source depth, direction of rapture, and site geology. It is worth to mention that if the ground motion model is used to estimate the response spectra for a structure in another region, where the distribution of scenarios was different than the one used to create the model, the prediction would be biased.

According to ASCE 07-10 and the area of Egypt where the models of this study were chosen to take place, Figure 2 shows the design and maximum considered response spectra chosen for the conducted analysis. Where, DBE is design basis earthquake, DBE is defined to have a $90 \%$ probability of non-exceedance in a 50-year-exposure period, which is equivalent to a recurrence interval of 474 years, in other words; the earthquake which the structure is required to safely withstand with repairable damage. MCE is maximum considered earthquake, can be defined as an earthquake that is expected to occur once in approximately 2,500 years; it has a $2 \%$ probability of being exceeded in 50 years. As commonly known, building codes in many localities will require non-essential buildings to be designed for "collapse prevention" in an MCE, so that the building remains standing where allowing for safety and escape of occupants rather than full structural survival of the building. The designer should prevent building collapse under values of SA with $2 \%$ probability of exceedance in 50 years. Having a capacity to prevent collapse of buildings under MCE codes aimed to make sure that buildings are designed for SA corresponding to DBE where the value of SA was found equal to 2/3 that of MCE. Accordingly, SA for MCE is equal 1.50 times that of DBE. The geometric nonlinear response of the buildings was determined using linear analysis considering the $\mathrm{P}-\Delta$ effect due to the gravity loads. 


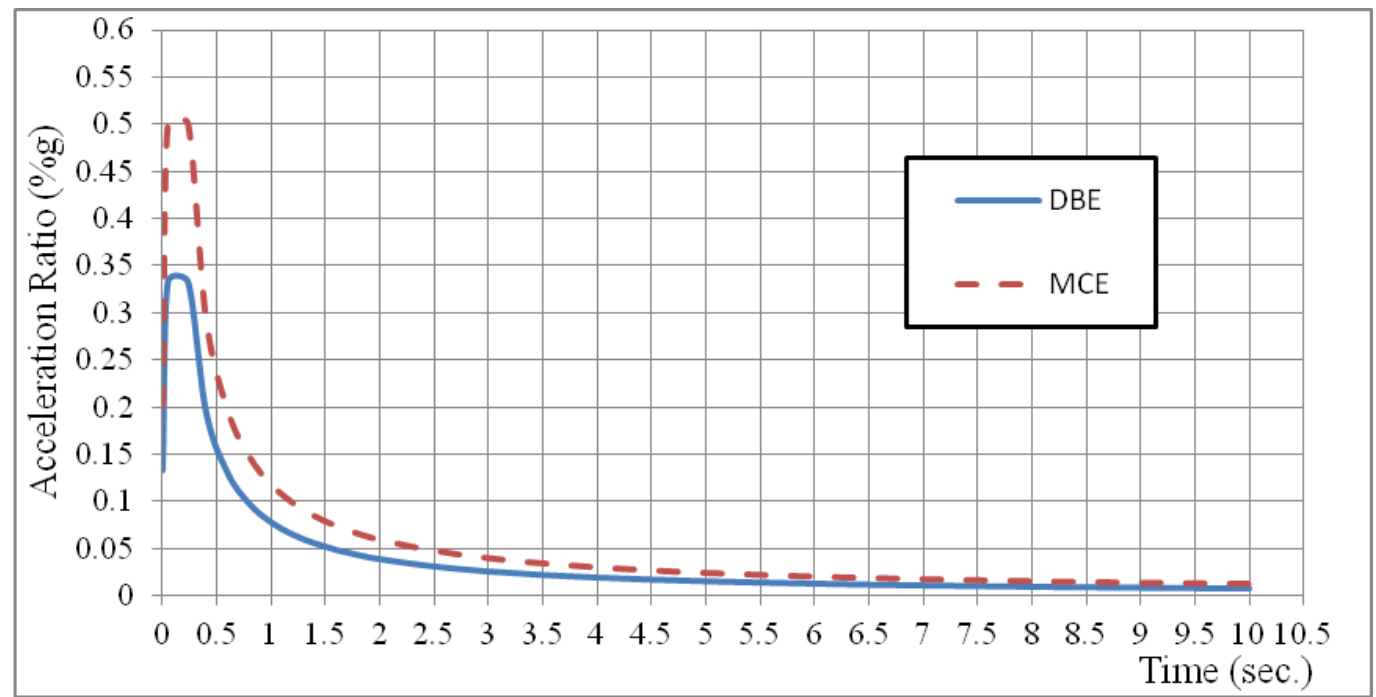

Figure 2: Response spectrum according to the ASCE 07-10 code [4].

Cairo, Egypt is the place considered to be the location of the models investigated in this study. Thus, according to the ASCE 07-10 provisions, the seismic parameters, related to this location, were found to be as following: the $0.2 \mathrm{sec}$ spectral acceleration $S_{\mathrm{s}}=0.5$, the $1.0 \mathrm{sec}$ spectral acceleration $S_{1}=0.117$, long period transition period=20 and the soil type is B (very dense soil and soft rock).

The numerical coefficient $(\mathrm{R})$ which is representative of the inherent over strength and global ductility capacity of lateral force-resisting systems was found to be 5.0, system over-strength $\left(\Omega_{0}\right)$ was found to be 2.5 , deflection amplification factor $\left(C_{d}\right)$ was found to be 4.5 and the building importance factor (I) will be 1.25 . The numerical coefficient $\left(\mathrm{C}_{t}\right)$ was found to be 0.02. For mass source, dead loads factor was taken to be 1.0 and live loads factor was taken to be 0.50 . The below paragraphs will give a brief for seismic performance factors, $R, \Omega_{\mathrm{o}}$ and $\mathrm{C}_{\mathrm{d}}$.

\section{Seismic design factors $R, \Omega_{o}$ and $C_{d}$}

Buildings behaviour following earthquakes had shown that a structure can be economically designed for the predicted elastic seismic design forces, while preserving the main objective of life safety performance. The reduction in seismic force used for design is done by using the seismic response modification factor; $\mathrm{R}$. The objective of the $\mathrm{R}$ factor is to simplify the structural design process such that using linearly elastic static analysis is sufficient to finalize building design.

While some members are detailed to provide ductility and accordingly they are designed to deform expected to deform in-elastically, other members are designed to remain elastic and experience a significantly higher seismic force level than that predicted based on actual design seismic forces. To account for this effect, the code uses a seismic force amplification factor, $\Omega_{\mathrm{o}}$; such that the calculated elastic design seismic forces can account for the real seismic forces in these members. $\Omega_{\mathrm{o}}$ is termed the structural over-strength factor in ASCE-702/05/10. To control drift or to check deformation capacity in some deformation-controlled members, a deflection amplification factor is introduced to predict expected maximum deformation from that produced by the design seismic forces. This factor is termed $C_{d}$ in ASCE 7-02/05/10.

The typical response envelope relating force to deformation is shown in Figure 3. The figure shows that the structure first responds elastically which are then followed by an inelastic response as the lateral forces are increased. A series of plastic hinges form throughout the structure, leading to yielding mechanism at the strength level $\mathrm{V}_{\mathrm{y}}$. 


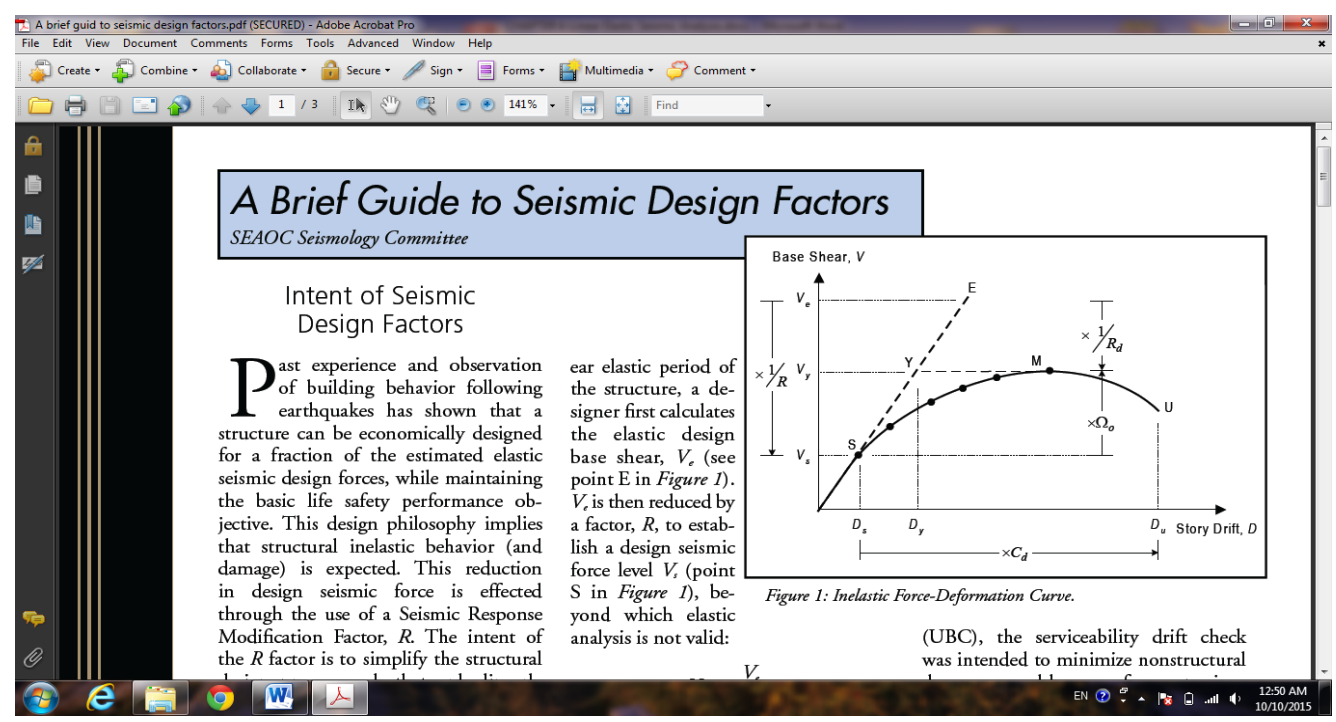

Figure 3: inelastic force-deformation curve.

The design method follows a simplified procedure. Based on the fundamental linearly elastic period of the structure a designer first calculates the elastic design base shear $V_{e}$ then $V_{e}$ is reduced by a factor $\mathrm{R}$, to establish a design seismic force level $\mathrm{V}_{\mathrm{s}}$, beyond which elastic analysis is not valid:

$$
\mathrm{V}_{\mathrm{s}}=\mathrm{V}_{\mathrm{e}} / \mathrm{R}
$$

To estimate internal forces that develop in force-controlled members for capacity design, the corresponding forces at the design seismic force level $\mathrm{V}_{\mathrm{s}}$ are then amplified by system overstrength factor $\Omega_{0}$, from an elastic analysis, the drift at the $V_{s}$ level is determined via the amplification of displacement values by a deflection amplification factor $C_{d}$ to estimate the maximum inelastic drift; this calculated drift is limited by building code values.

\section{Linear time history analysis}

Static procedures are appropriate when higher mode effects are not significant. This is generally true for short, regular buildings. Therefore, for tall buildings, buildings with torsional irregularities, or non-orthogonal systems, a dynamic procedure is required. In the linear dynamic procedure, the building is modelled as a multi-degree-of-freedom (MDOF) system with a linear elastic stiffness matrix and an equivalent viscous damping matrix.

The seismic input is modelled using either modal spectral analysis or time history analysis but in both cases, the corresponding internal forces and displacements are determined using linear elastic analysis. The advantage of these linear dynamic procedures with respect to linear static procedures is that higher modes can be considered. However, they are based on linear elastic response and hence the applicability decreases with increasing nonlinear behavior, which is approximated by global force reduction factors.

In linear dynamic analysis, the response of the structure to ground motion is calculated in the time domain, and all phase information is therefore maintained. Only linear properties are assumed. The analytical method can use modal decomposition as a means of reducing the degrees of freedom in the analysis. Thus, according to the ASCE 07-10 provisions, seismic ground motion for seven earthquakes, Imperial Valley 06; Mexico 1979, Duzce; Turkey 1999, Manjil; Iran 1990, Landers; USA 1992, Tottori 08; Japan 2000, Tottori 09; Japan 2000 and Darfield; New Zealand 2010, were chosen for analysis.

\section{The prototype building model}

A prototype building which comprise of a 50 story tower with total heights of $175.0 \mathrm{~m}$ is selected to perform the analysis. This building is modified from a real designed and constructed building to reflect a model for buildings with transfer floor. The same prototype building was previously scrutinized for the effect (among other parameters) of changing the level of the transfer system [2]. As such, in the current investigation, the location of the transfer floor is chosen at $20 \%$ of the total building height measured from the foundation and 
fixed throughout the investigation.

The building adopted in this study is symmetric in plan, and as such, avoids any torsional effects. The floor area is $20.0 \mathrm{~m}$ x $48.0 \mathrm{~m}$ where the spacing between the columns under the transfer floor is $8.0 \mathrm{~m}$ and while it is $4.0 \mathrm{~m}$ above the transfer floor. The typical story height is $3.5 \mathrm{~m}$. The transfer slab is $2000 \mathrm{~mm}$ thick solid plate supported on $1.0 \mathrm{~m} \times 4.0 \mathrm{~m}$ columns (underneath the slab) and supports $0.30 \mathrm{~m} \times 8.0 \mathrm{~m}$ shear walls above the slab. Plan of the building is shown in Figure 1.

\section{Finite element simulation}

The CSI finite element software package ETABS 2015 [8] is adopted in the current numerical analysis. This program is deliberately chosen as a first step in this research since it is one of the most widely adopted packages in design offices. A second step (to follow) will be to adopt another numerical analysis which considers more nonlinear structural and material response aspects.

A typical numerical model for the prototype building is shown in Figure 1. A threedimensional linear elastic model is adopted for each of the investigated analysis with different stiffness for the structural elements of the prototype building: slabs, walls and columns. Four cases are considered for the stiffness of the building's structural elements:

All structural elements have full stiffness (gross inertia $-I_{g}$ ).

All horizontal elements (slabs) have full stiffness (gross inertia $-\mathrm{I}_{\mathrm{g}}$ ) with all vertical elements (columns and walls) have reduced stiffness (cracked inertia $-\mathrm{I}_{\mathrm{cr}}$ ).

The transfer slab has full stiffness (gross inertia $-\mathrm{I}_{\mathrm{g}}$ ) with all other horizontal elements and vertical elements having reduced stiffness (cracked inertia $-\mathrm{I}_{\mathrm{cr}}$ ).

All elements have reduced stiffness (cracked inertia $-\mathrm{I}_{\mathrm{cr}}$ ).

According to ACI-318, cracked inertia for different elements is considered as: $\mathrm{I}_{\mathrm{cr}}$ (columns) = $0.7, \mathrm{I}_{\mathrm{cr}}$ (walls) $=0.35-0.7$; based on cracking conditions of walls and the governing failure condition of wall (axial or flexure), $\mathrm{I}_{\mathrm{cr}}$ (beams) $=0.35$ and $\mathrm{I}_{\mathrm{cr}}$ (slabs) $=0.25$.

The main purpose of the current analysis is to compare the building's response for each of the above mentioned case. As mentioned earlier, this is only a first step in a wider research aiming at producing design recommendations to be adopted for analysis of these kind of buildings.

\section{Seismic Response of the Prototype Building Model}

In this section, the global behavior of the prototype building will be presented. The results of the model include the shear distribution, base shear relative to periodic time, transfer floor shear force, moment distribution, drift distribution, displacement and mass participation ratios. A sample of the results is plotted in the Y-direction of the building (Figure 1) with almost a typical behavior recorded in the $\mathrm{X}$-direction.

\section{Inter-story drift}

Figure 4 shows a plot of the inter-story drift distribution over the building height. For all cases of inertia, the drift below the transfer floor reaches a maximum value midway between the foundation and transfer floor level and then decreases gradually up to the transfer floor location.

Above the transfer floor, the drift begins to increase till it reaches a maximum value in the vicinity of the roof level. It was previously indicated [2] that for higher transfer floors, the abrupt change in the inter-storey drift above and below the transfer structure becomes more serious. It is evident from Figure 4.a that the effect of stiffness reduction for columns and walls is more pronounced above the transfer floor with an increase in the drift values by about $10 \%$. It is also noted that stiffness reduction of all the structural elements except the transfer floor slab increases the drift by about $25 \%$, while the stiffness reduction for all structural elements increases the drift by about $35 \%$. The effect of transfer floor stiffness on the drift, relative using full stiffness for all structural elements, is about $10 \%$. 


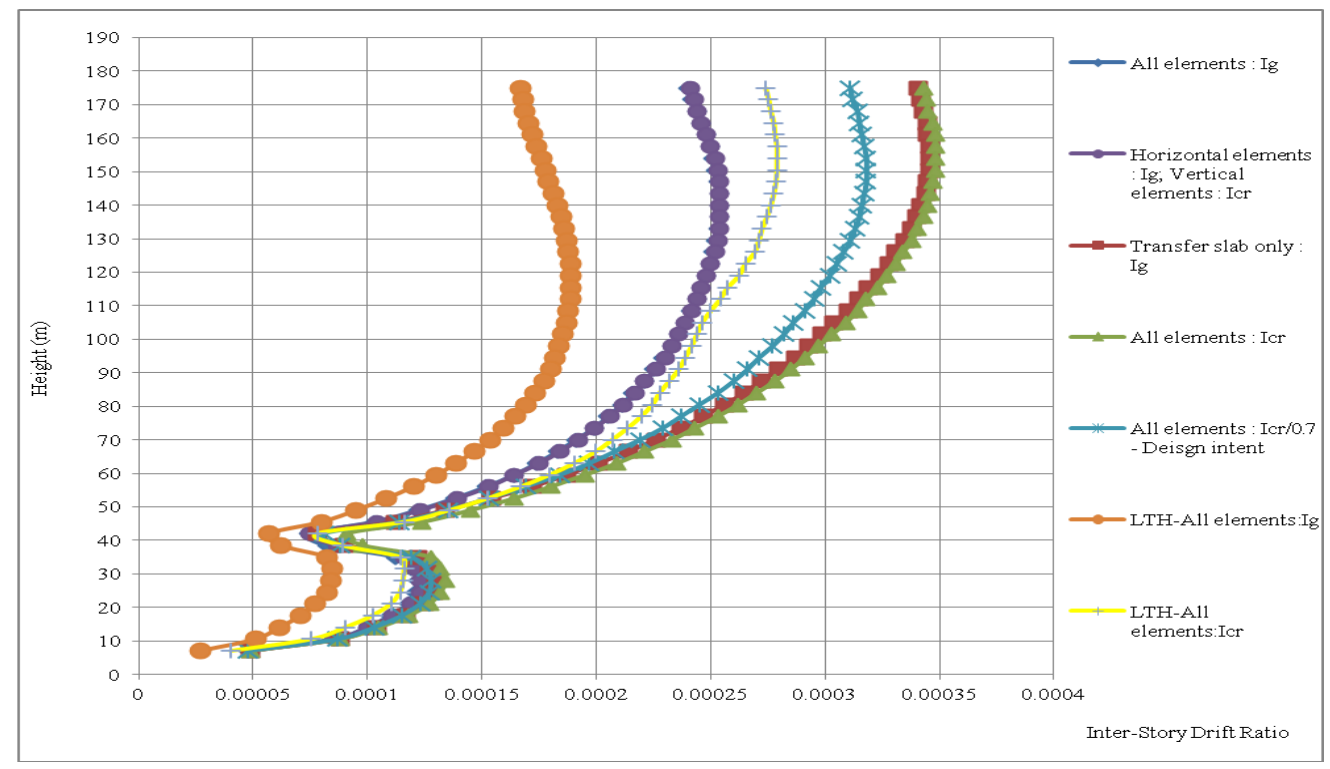

\section{Lateral displacement}

Figure 4: Inter-story drift in the Y-direction due seismic analysis.

A plot of the lateral displacement distribution over the building height is shown in Figure 5.

It is evident that the lateral building displacement matches a flexural behavior mode till the transfer floor level where a large force hit the building due to the huge mass of the transfer floor causing large displacement to take place. Displacement from foundation up to the transfer floor level simulates a fixed-fixed flexural member, where above the transfer floor level, the building acts as a free cantilever with its base fixed at the transfer floor. Stiffness reduction of vertical elements has an effect which is significant above the transfer floor level. This effect increases with the increase in height, reaching its maximum values at the roof floor. The lateral displacement resulting from using reduced vertical elements is about $25 \%$ more than its value corresponding to using full stiffness. Reducing the vertical and horizontal elements stiffness with or without the reduction of the transfer floor stiffness has almost the same results: the lateral displacement almost doubled. As such, it can be concluded that reducing the transfer slab stiffness has minor effect on the lateral displacement of the building.

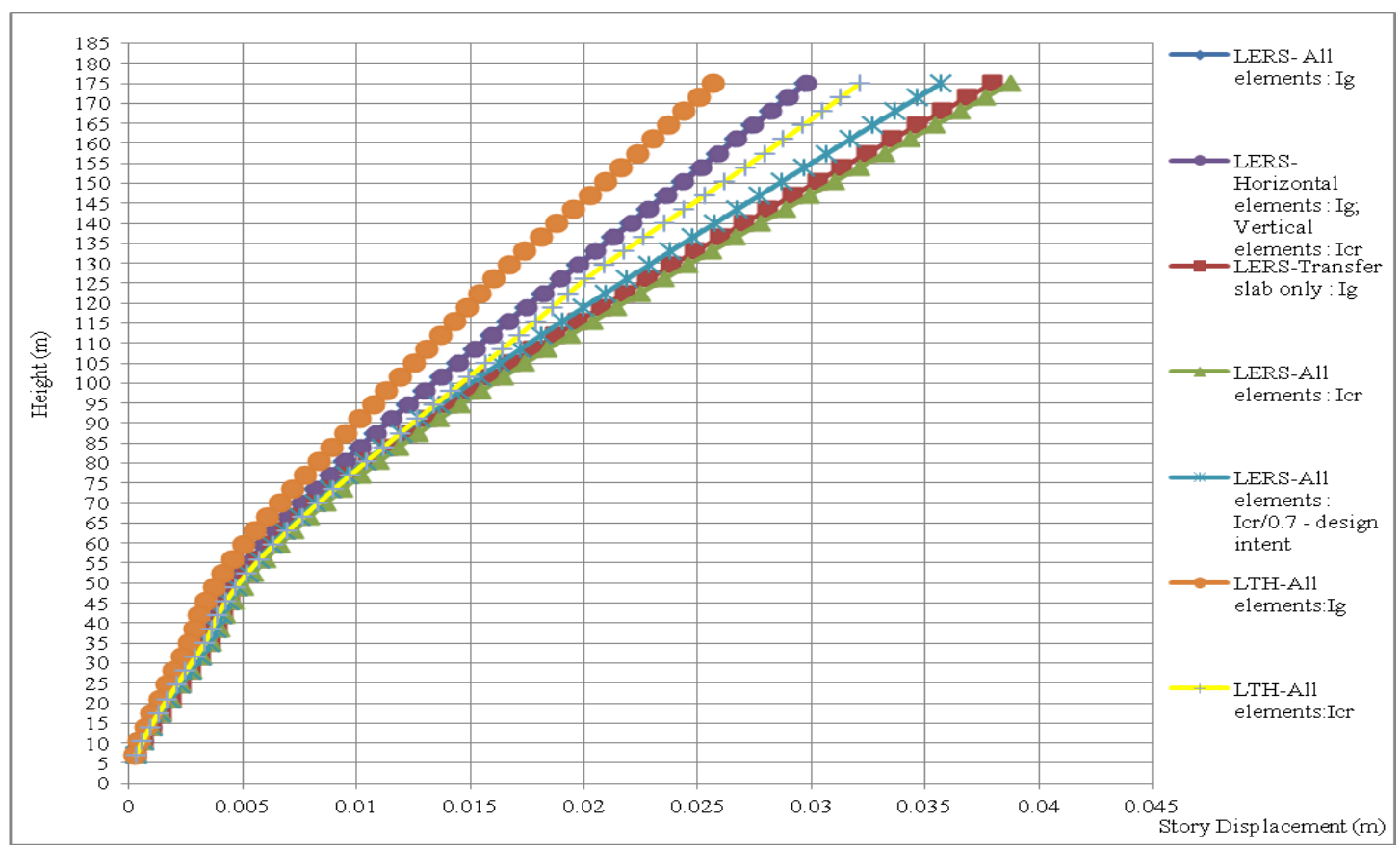

Figure 5: Story Displacement in the $\mathrm{Y}$-direction due seismic analysis. 


\section{Story-shear}

Figure 6 shows a plot of the story-shear distribution over the building height. The figure shows that a significant reduction in the story shear above the transfer slab level in the four investigated stiffness cases due to the sudden change in overall building stiffness at the slab level. The effect of reducing the stiffness of the vertical structural elements is small: about $15 \%$ reduction in story shear is recorded compared to values recorded for adopting full vertical stiffness in the analysis. The figure shows also that the story shear distribution/values are almost similar for cases of using reduced stiffness or full stiffness of transfer slab with cracked vertical elements. Stiffness reduction of all horizontal and vertical elements results in decreasing the story shear by about $30 \%$.

\section{Story-moment}

A plot of the story-moment distribution over the building height is shown in Figure 7. The figure reveals that the story-moment distribution has a counter flection point at the vicinity of the transfer floor level. Reduction of the vertical elements stiffness has an effect of reducing the values of story moment by about $10 \%$. Transfer slab stiffness almost has no significant effect on the values of the story moment distribution. The building is behaving like a cantilever where the value at the top floor is almost the same regardless adopting reduced or full stiffness for the structural elements. On the other hand, reduction the stiffness of all horizontal and vertical elements decreases the story moment by about $30 \%$ below the transfer floor level.

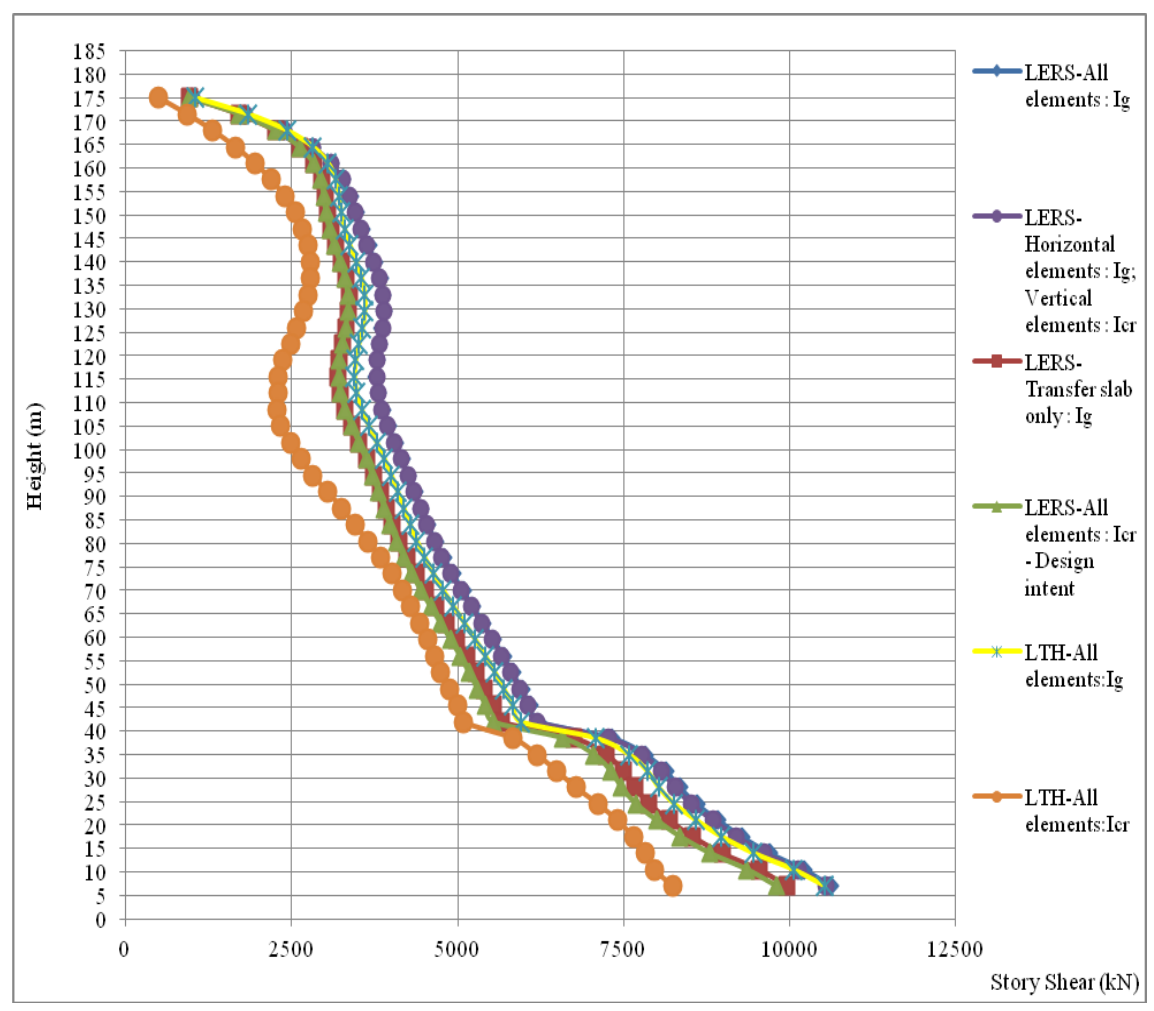

Figure 6: Story shear in the Y-direction due to seismic analysis

\section{Base shear}

Figure 8 shows the plot of the base shear for the four different cases of stiffness. The comparison is made for the three cases of loading (equivalent static loading, response spectrum and time history analysis) without any scaling. It is evident from the figure that the base shear resulting from the elastic response spectrum and the linear time history analyses is far lower than that resulting from the equivalent static load analysis. In the four cases considered for the structural elements stiffness, the base shear resulting from the response spectrum and time history analyses only differs by about 5\%: using reduced stiffness actually increases the base shear values in these two analyses by this marginal ratio. Generally, base shear resulting from the linear time history is marginally less than that resulting from the response spectrum analysis. 


\section{Mass participation ratio}

A plot of the mass participation ratio for every mode is plotted in Figure 9. The stiffness reduction decreased the mass participation percentage for every mode. The governing mode with the largest mass participation percentage for the various cases of stiffness is obviously the translation mode. The analyses case of reduced stiffness for all elements with or without full transfer slab stiffness has approximately the same percentage for the mass participation.

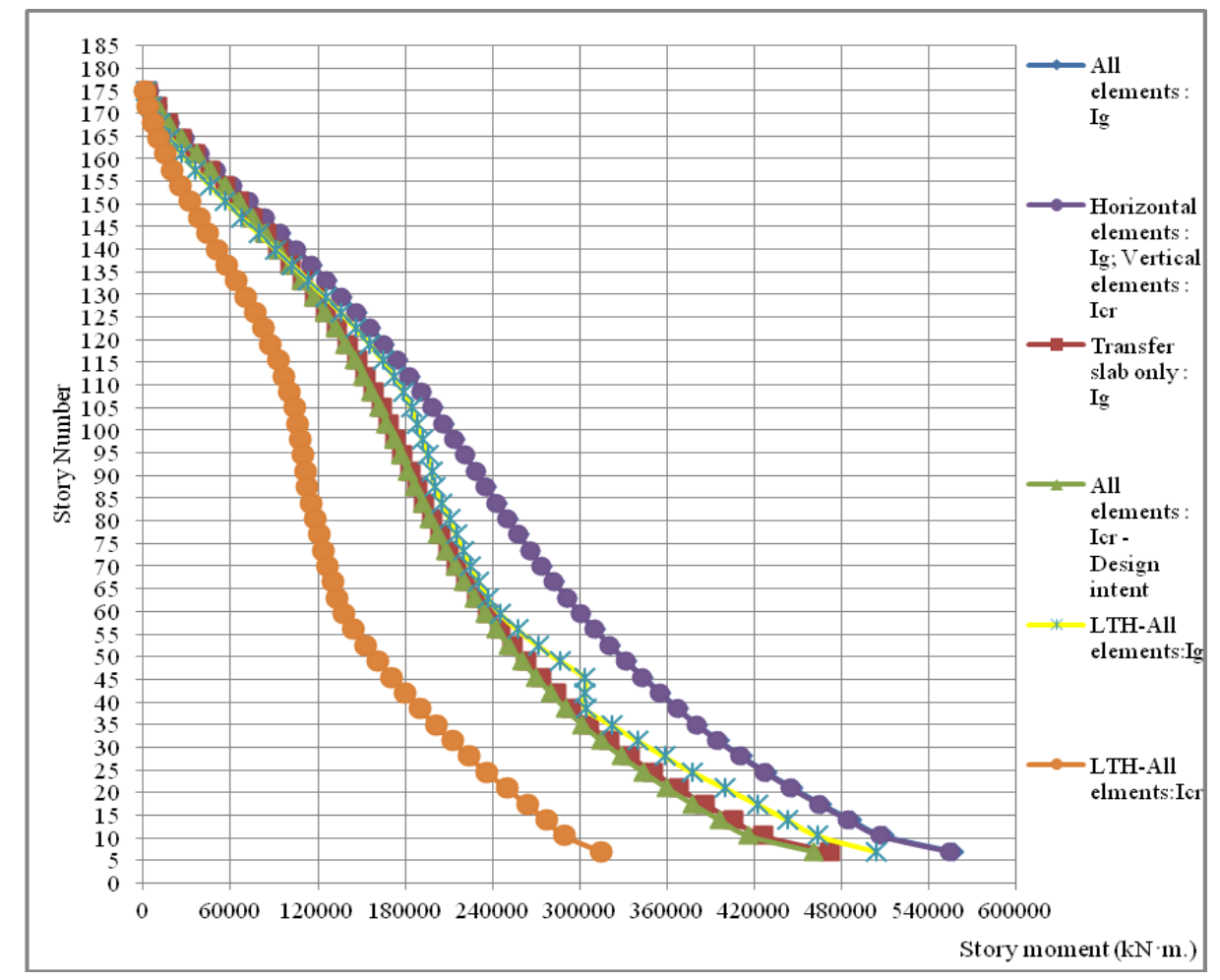

Figure 7: Story Moment in the Y-direction due to seismic analysis.

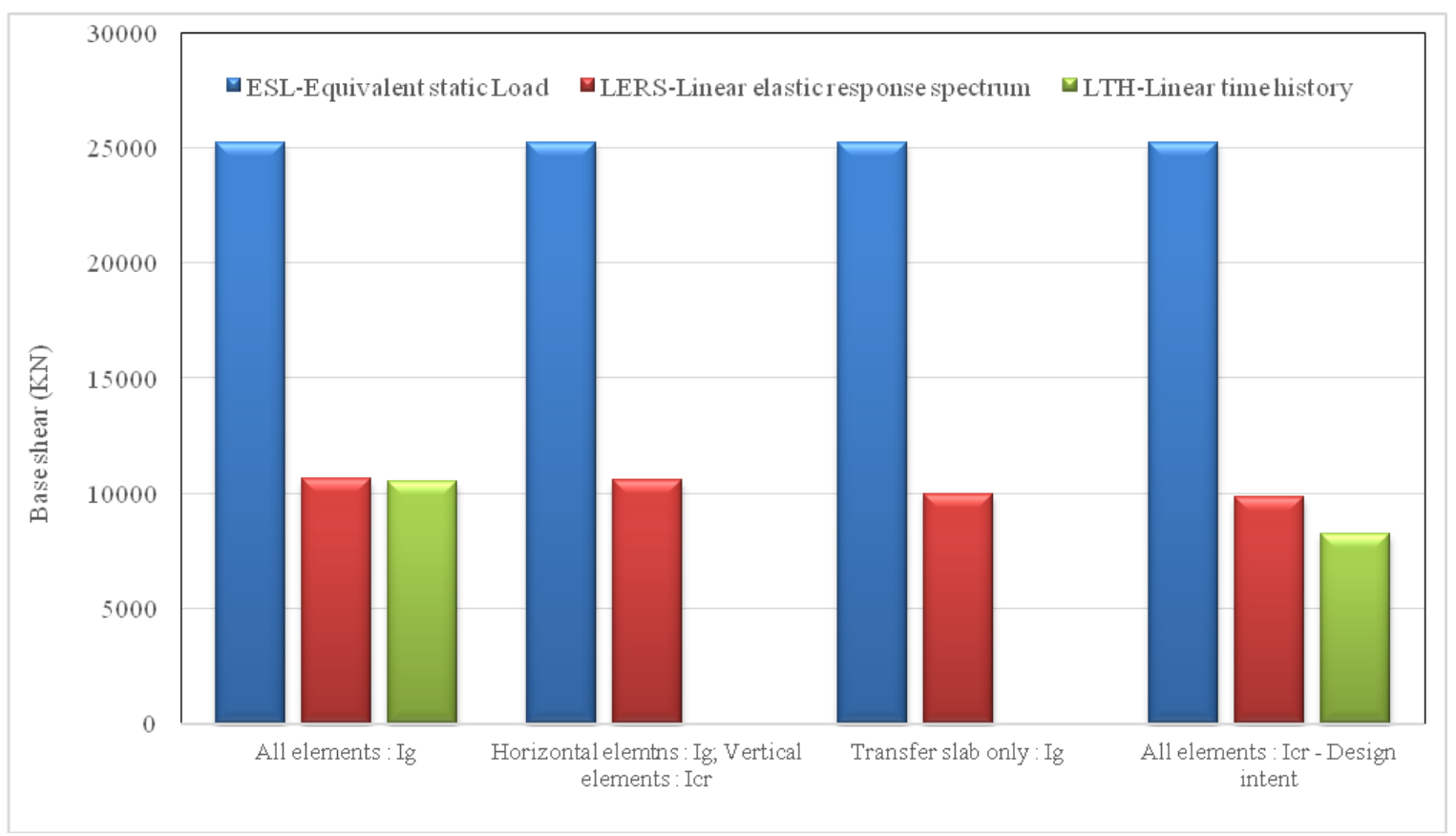

Figure 8: Base shear in the Y-direction due to seismic analysis. 


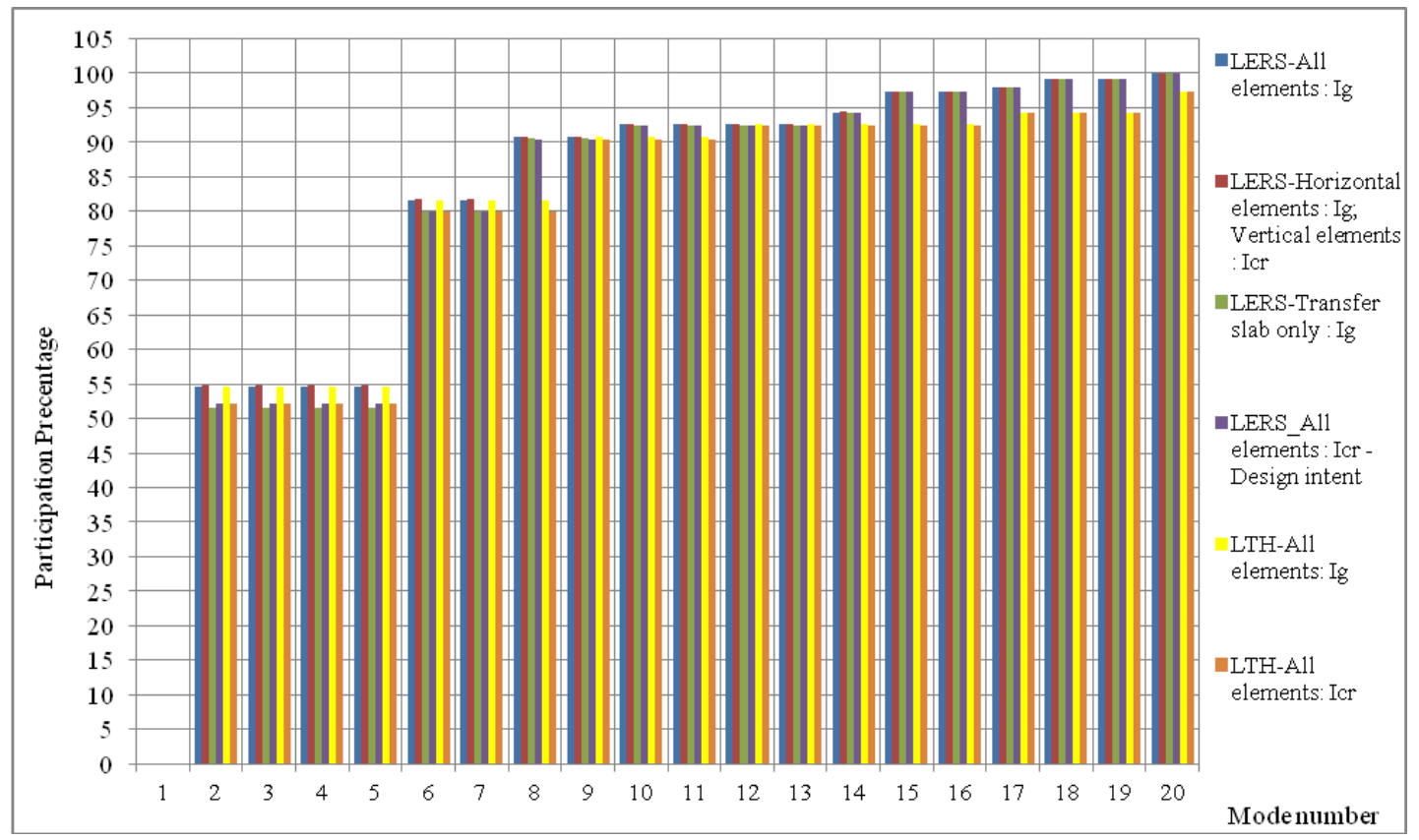

Figure 9: Modal Mass Participation Ratio in the $\mathrm{Y}$-direction due to seismic analysis.

\section{Natural frequency}

Figure 10 shows the building's natural frequency corresponding to each considered mode for the four analyzed stiffness cases. As expected, this figure proves that the first mode is the mode with least values for frequency for all cases of stiffness. The reduction of the stiffness decreases the natural frequency in a reverse order to the mode number. The reduction of stiffness of the horizontal structural elements (slabs) has more effect on frequency compared to that of the vertical elements. Reduction of the transfer slab stiffness has no significant effect on the frequency of the building.

\section{Conclusions}

Numerical analyses for a prototype building with a transfer floor have been performed. An equivalent static loading, a response spectrum and a time history were adopted in the analysis. A comparative study is presented on the effect of using reduced stiffness for the different structural elements of the building; as currently recommended by the code of practice. The essential prerequisite of structural irregularity increases the importance of dynamic analysis to take into account the actual force distribution. Although spectrum scaling is the simplest approach, it is unjustifiable and basically not accurate. Conclusions can be summarized as follow:

a. Reduction in stiffness of horizontal element reduces seismic forces by $25 \%$ compared to gross inertia for all elements. Reduction in stiffness of vertical elements only reduces the seismic forces by approximately 15\%. Also reduction in stiffness of transfer slabs reduces the seismic forces induced in structural elements to $25 \%$ compared to the one obtained in case of gross inertia is inherited in all elements. 


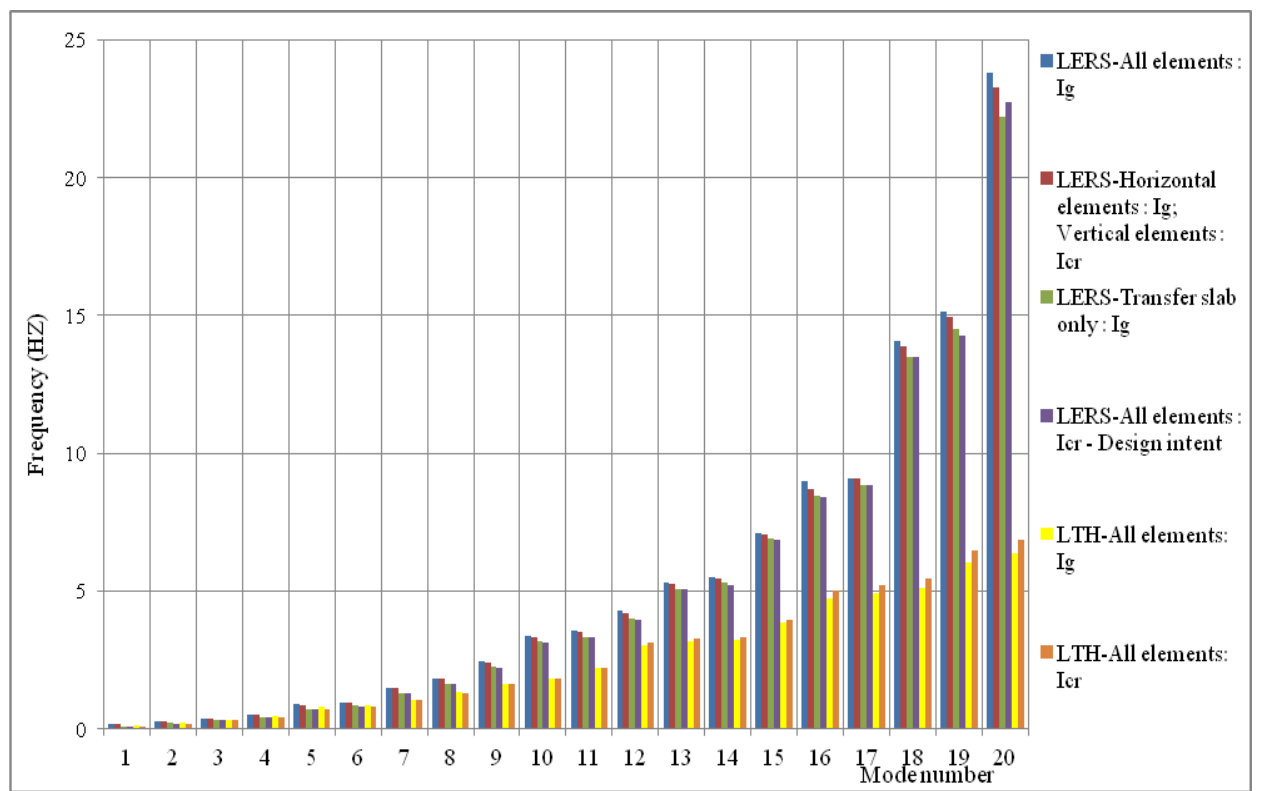

Figure 10: Natural Frequency due to response spectrum analysis

b. Starting from $80 \%$ of the building's height above its base, reduction in stiffens in any structural elements no longer affects values of shear and moment.

c. Regarding the base shear, values for base shear resulting from the equivalent static load method is greater than values resulting from elastic response spectrum method and linear time history method by approximately $70 \%$. Base shear due to linear time history analysis is less than values due to elastic response spectrum analysis by about 5 to $10 \%$.

d. Maximum values of drift due to elastic response spectrum analysis is at height equal of $2 / 3$ total height of building. Minimum values of drift due to elastic response spectrum analysis is at transfer floor level with similar values for all of different stiffness category. Values of drift at roof floor are between values at transfer floor and maximum values at $2 / 3$ of total height.

e. Reduction in vertical elements stiffness is more pronounced above transfer floor with an increase of values by $10 \%$. Reduction in stiffness of horizontal elements, except for transfer floor increases the drift by $15 \%$. Using reduced stiffness increases the drift by about $35 \%$ above that obtained by using gross inertia for all elements.

\section{Acknowledgment}

This work was done under the auspices of Dar Al-Handasah, Shair and Partners. The authors would like to acknowledge this in terms of providing all necessary hardware and/or software to perform this research. This is done as a part of DAR Al-Handasah research vision and professional development activities which aim at enhancing the technical ability of Dar's engineers and globally improving and augmenting the engineering knowledge.

\section{References}

1. Li C.S., Lam S. S. E., Zhang M. Z., and Y. L. Wong Y. L. Shaking Table Test of a 1:20 Scale High-Rise Building with a Transfer Plate System. ASCE Journal of Structural Engineering, Vol. 132, No. 11, 2006, pp. 1732-1744.

2. El-Awady, A.K., Okiel, H.O., Abdelrahman, A.A., Sayed-Ahmed, E.Y. Seismic Behaviour of High-Rise Buildings with Transfer Floors. Electronic Journal of Structural Engineering, Vol. 14, No. 2, 2014, pp. 57-70,

3. Yong L., Tassios T.P., Zhang G.F., and Vintzileou E. Seismic Response of Reinforced Concrete Frames with Strength and Stiffness Irregularities. ACI Structural Journal, Vol. 96, No. 2, 1999, Title no. 96-S24

4. Su R.K.L. Seismic Behaviour of Buildings with Transfer Structures in Low-toModerate Seismicity Regions. Electronic Journal of Structural engineering eJSE 
international Special Issue 1: Earthquake Engineering in the low and moderate seismic regions of Southeast Asia and Australia. 2008, pp. 99-109.

5. Al-Ali, A. A. K., and Krawinkler, H. Effects of Vertical Irregularities on Seismic Behaviour of Building Structures. Department of Civil and Environmental Engineering, Stanford University, San Fransisco. Report No. 130. December 1998.

6. Yoshimura M. Nonlinear Analysis of a Reinforced Concrete Building with a Soft First Storey Collapsed by the 1995 Hyogoken- Nanbu Earthquake. Cement and Concrete Composites, Vol. 19, 1997, pp. 213-221.

7. Abdelbasset Y.A., Sayed-Ahmed E.Y., Mourad S.A. High-Rise Buildings with Transfer Floors: Design Recommendations for Drift Calculations. Proceedings 37th IABSE Symposium: Engineering for Progress, Nature and People. Madrid, Spain 3-5 Sept. 2014. pp. 637-644.

8. ETABS 2015, Integrated Analysis, Design and Drafting of Buildings. CSI Compute \& Structures Inc. 2015. 